\title{
Alkyl Transfer Steps in the Catalytic Alkylation of Benzene, Tolvene, and Cyclohexane
}

\author{
G. PARRAVANO \\ Department of Chemical and Melallurgical Engineering. \\ University of Michigan, Ainn Arbor, Michigan 48104
}

Received April 6, 1971

\begin{abstract}
The rate of the catalytic redistribution of isotopic carbon in binary mixtures of benzene and toluene, benzene and ethylbenzene, toluene and xylene, toluene and ethylbenzene, cyclohexane and methylcyclohexane was investigated over supported $\mathrm{Pt}, \mathrm{Ir}, \mathrm{Ru}$, and $\mathrm{Au}$. The influence of the following experimental variables was assessed: hydrocarbon partial pressure ratios, $3 \times 10^{-3}$ to 30 ; temperature, 185 to $400^{\circ} \mathrm{C}$; catalyst support, $\mathrm{Al}_{2} \mathrm{O}_{3}, \mathrm{MgO}$; catalyst acidity and basicity, and method of catalyst preparation. The results are discussed in the framework of processes of competitive and reactive chemisorption of hydrocarbon mixtures. The dependence of the reaction rate upon the hydrocarbon partial pressure ratio is considered in detail. Displacement effects were found when xylene isomers were present simultaneously. The insight that the carbon redistribution reaction may provide in investigations on the thermodynamic and kinetie aspects of alkyl transfer steps at catalytic surfaces is pointed out.
\end{abstract}

Alkyl transfer steps figure prominently in catalytic alkylations. Their characteristics are often indirectly gleaned from information on the rate of net alkylation reactions. However, individual alkyl transfer steps cannot be observed easily in a net alkylation process operating at steady state. It is more convenient and direct to follow alkyl transfer at catalytic surfaces by suitable isotopic labeling of molecular species differing in composition by a $\mathrm{CH}_{2}$. or higher alkenyl group. Consider the reaction between a $\mathrm{CH}_{2}$ donor, $\mathrm{AR}$, and a $\mathrm{CH}_{2}$ acceptor, $\mathrm{A}$, at a catalytic surface,

$$
A R(g) \rightarrow A(g)+R(s)
$$

where $\mathrm{R}$ is a $\mathrm{CH}_{2}$ group and the suffixes $\mathrm{g}$ and $s$ indicate gas and surface, respectively. Reaction (1a) represents a key step in catalytic alkylations. To assess its role in the net reaction, the influence of catalyst and reaction variables on the step rate must be measured. To this end, consider transfer step (1a) taking place at the same eatalytic surfare simultaneously with the following step:

$$
{ }^{*} \mathrm{~A}(\mathrm{~g})+\mathrm{R}(\mathrm{s}) \rightarrow{ }^{*} \mathrm{AR}(\mathrm{g}) .
$$

The sequence of reaction steps (1a) and (1b) corresponds to the exchange reaction:

$$
\mathrm{Al}(\mathrm{g})+{ }^{*} \mathrm{~A}(\mathrm{~g}) \rightarrow \mathrm{A}(\mathrm{g})+{ }^{*} \mathrm{Al}(\mathrm{g}) .
$$

The asterisk in reactions (1) and (1b) represents an isotopic carbon atom. Since there is no change in gas phase composition during the occurrence of reaction (1) and neglecting kinetic isotopic effects, the rates of reaction steps (1a) and (1b) are equal to that of the overall reaction (1). Consequently, the rate of reaction (1) gives directly that of the $\mathrm{CH}_{2}$ transfer (1a). These considerations indicate that a convenient manner to study the rate of catalytic transfer of $R$ between $A R$ and $A$ is to contact a mixture of $A R$, " AR, and $A$ with the catalytic surface and follow the rate of appearance of ${ }^{*} \mathrm{~A}$. We have carried out these experiments with $R$ being a methylene or ethylene group. In particular, the transfer 
was investigated between the hydrocarbons of the following binary mixtures: benzene(BE)-toluene (TO); BE-ethylbenzene (EBE); TO xylene (XE) ; TO-EBE; cyclohexane (CHA) - methylcyclohexane (MCHA). In the case of XE, the three isomers were investigated independently and also in binary combinations. The range of temperature employed was between 185 and $400^{\circ} \mathrm{C}$ and that of the ratio of hydrocarbon partial pressure varied between $3 \times 10^{-3}$ to 30 . Metal catalysts used were $\mathrm{Pt}, \mathrm{Ir}, \mathrm{Au}$, and $\mathrm{Ru}$ supported on $\mathrm{Al}_{2} \mathrm{O}_{3}$ and $\mathrm{MgO}$. The possibility of following the rate of reaction (1) was suspected on the basis of previous studies showing that when ${ }^{14} \mathrm{CH}_{3}$ TO was catalytically hydrodealkylated, the $\mathrm{BE}$ produced was free from radioactivity (1). This was taken as an indication of a selective splitting of the $\mathrm{CH}_{3}$ group without skeletal rearrangements.

\section{Experimental Methods}

Reagent grade hydrocarbons were used without further purification and high purity $\mathrm{He}$ gas was used as a carrier. Stock solutions of ${ }^{14} \mathrm{C}$-labeled $\mathrm{BE}$, TO, and CHA were made from milligram portions of radioactively concentrated samples $(0.5$ to $3 \mathrm{mCi}$. The catalysts tested included: Pt $(0.4$ wt $\%)-\mathrm{Al}_{2} \mathrm{O}_{3}, \mathrm{Pt}(0.4$ wt $\%)-\mathrm{Al}_{2} \mathrm{O}_{3}$ fluorided, Ir $(0.7$ wt $\%)-\mathrm{Al}_{2} \mathrm{O}_{3}, \mathrm{Ru}$ (2 wt $\%)-\mathrm{Al}_{2} \mathrm{O}_{3}, \mathrm{Au}(0.3$ wt $\%)-\mathrm{Al}_{2} \mathrm{O}_{3}, \mathrm{Au}(2$ wt \%)-MgO. The $\mathrm{Pt}$ catalysts were commercial samples, in the form of $1 / 16$ in. diameter spheres. Ir, $\mathrm{Ru}$, and $\mathrm{Au}$ eatalysts were prepared by impregnation of high area powdered $\mathrm{Al}_{2} \mathrm{O}_{3}$ with an $\mathrm{H}_{2} \mathrm{O}$ solution of the metal chloride, followed by thermal decomposition. Details on these preparations have been described previously $(2,3)$. Part of the Ir catalyst was treated with sufficient amounts of $\mathrm{NaHCO}_{3}$ solution to add to it $1 \% \mathrm{NaHCO}_{3} . \mathrm{Au}$ catalysts were also prepared by reduction of the $\mathrm{Au}$ salt with $\mathrm{HCHO}$. Catalyst pretreatment included in situ heating in a stream of $\mathrm{H}_{2}$ at $370^{\circ} \mathrm{C}$ for $1 \mathrm{hr}$, except for Pt-fluorided $\mathrm{Al}_{2} \mathrm{O}_{3}$ for which the $\mathrm{H}_{2}$ treatment was carried out at $450^{\circ} \mathrm{C}$. The rate of reaction (1) was studied in a flow system at a total pressure of 1 atm. Appropriate amounts of the various hydrocarbon combinations were flowed in a stream of $\mathrm{He}$ through the catalyst bed $(1-5 \mathrm{ml})$. The exit stream was analyzed and fractionated by gas chromatography; and radioactivity counting on each fraction was carried out by liquid scintillation techniques. Details of the experimental setup and procedure have been published previously (2). The treatment of the experimental results followed the method already described (2). The rate of reaction (1b) is given by:

$$
\frac{1}{w} \frac{d n_{\mathrm{AR}}}{d t}=k_{c} p *_{\mathrm{A}}-k_{c}^{\prime} p^{*} \mathrm{AR},
$$

where $w$ catalyst weight, $n_{\mathrm{AR}}^{*}$ moles of ${ }^{*} \mathrm{AR}$ and $k_{c}, k_{c}^{\prime}$, rate coefficients of the forward and reverse step of reaction (1b). Integration of Eq. (2) for a flow reactor yields:

$$
k_{c}=\frac{\dot{V}}{W R T} \frac{1}{1+(1 / \beta)} \ln \frac{1}{1-\beta},
$$

where $\dot{V}$, volumetric flow rate, $\beta=p_{\mathrm{AR}} / p_{\mathrm{A}}$, and the reaction conversion

$$
\alpha=\frac{p_{{ }^{\mathrm{A}}}}{\left(p_{*_{\mathrm{A}}}\right)_{e}}=\frac{p_{*_{\mathrm{A}}}}{\left(p_{*_{\mathrm{A}}}\right)_{0}} \frac{1+\beta}{\beta} .
$$

The subscripts $e, 0$ refer to equilibrium and initial conditions, respectively. The possibility of studying the rate of the transfer step (1a), by following the rate of the exchange reactions (1) implied that no interference from side reactions took place. The experimental conditions were specifically chosen to fulfill this point. The absence of products was checked in each run. The former appeared at temperature or partial pressure ratios higher than those reported. $\mathrm{C}_{2} \mathrm{H}_{4}$ desorption was found absent. This may have been due to the low equilibrium pressure corresponding to the temperature and hydrocarbon ratios employed $\left[\sim 10^{-4}\right.$ atm for $\left(p_{\mathrm{TO}} / p_{\mathrm{BE}}\right)=1$ at $\left.380^{\circ} \mathrm{C}\right]$ and $/$ or to low desorption rate. The conditions generally employed for the catalytic alkylation of BE (4) and TO (5) are somewhat different from those of the present study.

\section{Experimental Results}

A direct check for the establishment of equilibrium during the course of reaction 


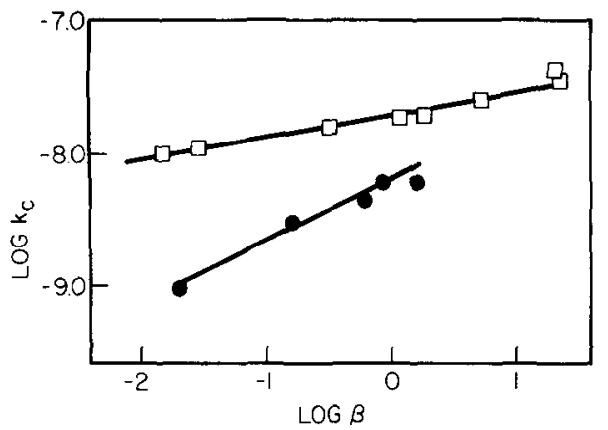

FIG. 1. $k_{c}$ versus $p_{\mathrm{TO}} / p_{\mathrm{BE}}=\beta$ for reaction $(1)$ : Pt $(0.4$ wt $\%)-\mathrm{Al}_{2} \mathrm{O}_{3}(\square) ;{ }^{*} \mathrm{BE}+\mathrm{FB}$ on $\mathrm{Pt}(1$ wt $\%$ )-fluorided $\mathrm{Al}_{2} \mathrm{O}_{3}(\odot), 390^{\circ} \mathrm{C}$.

(1) was not possible due to the smallness of the equilibrium pressure of possible olefinic intermediates. The former was assumed on the basis of the reversibility and reproducibility of the results. Reaction conversions up to $50 \%$ were obtained with contact times of the order of 1 to $10 \mathrm{sec}$ at

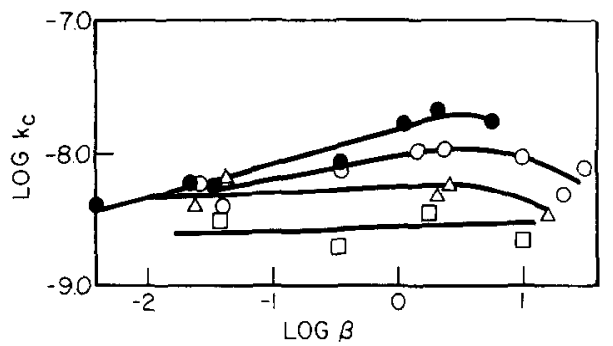

Fig. 2. $k_{c}$ versus $p_{\mathrm{TO}} / p_{\mathrm{BE}}=\beta$ for reaction (1) catalyzed by $\mathrm{Pt}\left(0.4\right.$ wt $\%$ )-fluorided $\mathrm{Al}_{2} \mathrm{O}_{3}$ : (口)

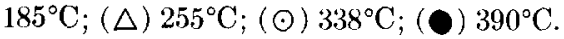

$390^{\circ} \mathrm{C}$. The effect of $\beta$ on $k_{e}$ for the mixtures $\mathrm{BE}-\mathrm{TO}$ and $\mathrm{BE}-\mathrm{EBE}$ on Pt catalysts in the temperature range 187 to $393^{\circ} \mathrm{C}$, is shown in Figs. 1 and 2. Figures 3 and 4 summarize the observation on $\mathrm{Ir}$ and $\mathrm{Ru}$ catalysts for BE-TO mixtures in the temperature range 276 to $390^{\circ} \mathrm{C}$, while Fig. 5

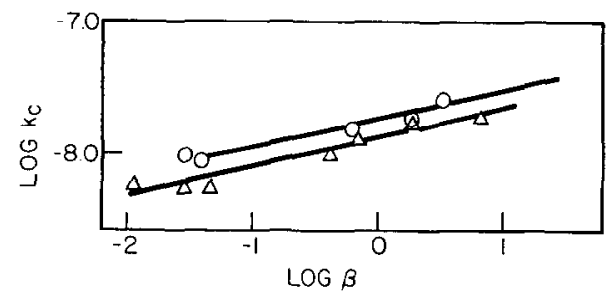

FIG. 3. $k_{c}$ versus $p_{\mathrm{TO}} / p_{\mathrm{BE}}=\beta$ for reaction (1): $(\odot) \mathrm{Ir}(0.7 \mathrm{wt} \%)-\mathrm{Al}_{2} \mathrm{O}_{3} ;(\triangle) \mathrm{Ir}(0.7 \mathrm{wt} \%)-\mathrm{Al}_{2} \mathrm{O}_{3}+$ $1 \% \mathrm{NaHCO}_{3} ; 390^{\circ} \mathrm{C}$.

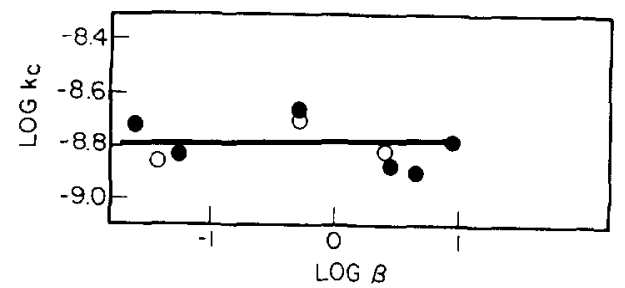

FIG. 4. $k_{c}$ versus $p_{t o} / p_{\mathrm{BE}}=\beta$ for reaction (1) catalyzed by $\mathrm{Ru}(2$ wt $\%)-\mathrm{Al}_{2} \mathrm{O}_{3}:(\odot) 336^{\circ} \mathrm{C}$; $390^{\circ} \mathrm{C}$.

presents the results obtained from experiments on $\mathrm{Au}$ catalysts. In Fig. 6, we show the experimental results of the hydrocarbon mixture $\mathrm{TO}-\mathrm{XE}$ on $\mathrm{Pt}-\mathrm{Al}_{2} \mathrm{O}_{3}$ at $390^{\circ} \mathrm{C}$, while results at 210,327 , and $390^{\circ} \mathrm{C}$ for $p$-XE on a similar catalyst are collected in Fig. 7. To obtain a direct indication of the

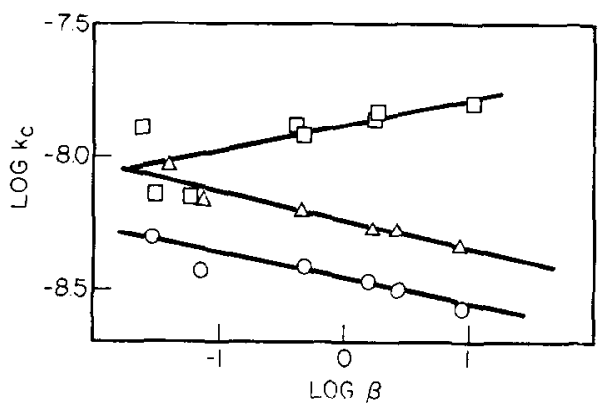

Fig. 5. $k_{c}$ versus $p_{\mathrm{TO}} / p_{\mathrm{BE}}=\beta$ for reaction (1): (O) Au (2 wt \%)-MgO prepared by reduction; $(\triangle)$ $\mathrm{Au}(0.3$ wt $\%)-\mathrm{Al}_{2} \mathrm{O}_{3}$ prepared by reduction; ( $\left.\square\right)$ $\mathrm{Au}(0.3 \mathrm{wt} \%)-\mathrm{Al}_{2} \mathrm{O}_{3}$ prepared by impregnation; $386^{\circ} \mathrm{C}$.

relative rate of reaction between $\mathrm{XE}$ isomers, experiments on mixed $\mathrm{XE}$ feeds were carried out by introducing to the reactor a mixture of $\mathrm{TO}+{ }^{*} \mathrm{TO}+\mathrm{XE}$ isomers. The results on the mixture $o-\mathrm{XE}+$ $m$-XE are reported in Fig. 8, while Fig. 9

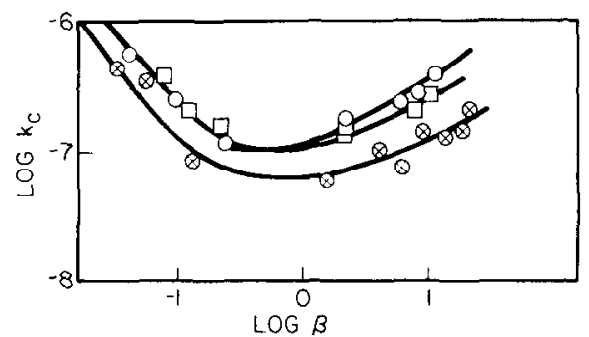

Fig. 6. $k_{c}$ versus $p_{\mathrm{TO}} / p_{\mathrm{BE}}=\beta$ for reaction (1)

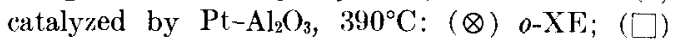
$m$-XF; (९) $p$-XF. 


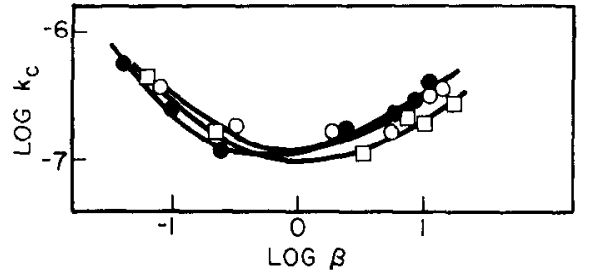

FiG. 7. $k_{c}$ versus $p_{\mathrm{XE}} / p_{\text {TO }}=\beta$ for reaction (1) catalyzed by $\mathrm{Pt}-\mathrm{Al}_{2} \mathrm{O}_{3}$ : ( $\square$ ) $210^{\circ} \mathrm{C}$; (O) $327^{\circ} \mathrm{C}$; (C) $390^{\circ} \mathrm{C}$.

shows those on the $o$ - $\mathrm{XE}+p$-XE mixtures at $390^{\circ} \mathrm{C}$. In Fig. 10, we have collected the results on the mixture TO-EBE catalyzed by $\mathrm{Pt}-\mathrm{Al}_{2}\left(\mathrm{O}_{3}\right.$ at $390^{\circ} \mathrm{C}$. Figure 11 shows the experimental data on the mixture CHAMCHA in the presence of $\mathrm{Pt}-\mathrm{Al}_{2} \mathrm{O}_{3}$ at $390^{\circ} \mathrm{C}$. The influence of temperature on re-

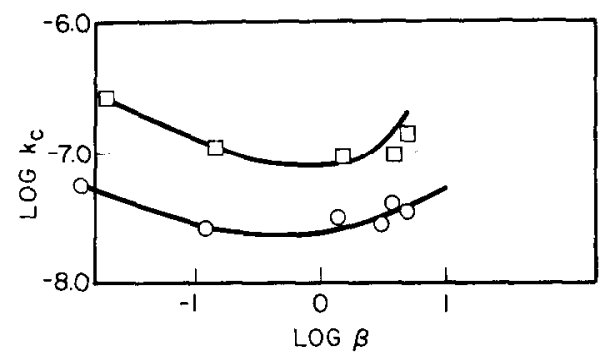

Fig. 8. $k_{c}$ versus $p_{\mathrm{To}} / p_{\mathrm{BE}}=\beta$ for mixed feed of $a$-XE $(\odot)$; and $m$-XE $(\square)$; in the presence of TO, reaction (1), catalyzed by $\mathrm{Pt}-\mathrm{Al}_{2} \mathrm{O}_{3}, 390^{\circ} \mathrm{C}$.

action (1) catalyzed by $\mathrm{Pt}-\mathrm{Al}_{2} \mathrm{O}_{3}$ is presented in Fig. 12. From these results an activation energy of about $2 \mathrm{kcal} /$ mole was calculated for $\mathrm{BE}-\mathrm{TO}$, while for $\mathrm{T}(\mathrm{)}-\mathrm{p}-\mathrm{XE}$ the activation energy was $\approx 0$.

\section{Discussion}

The significant conclusions which may be derived from the results collected in the previous section are:

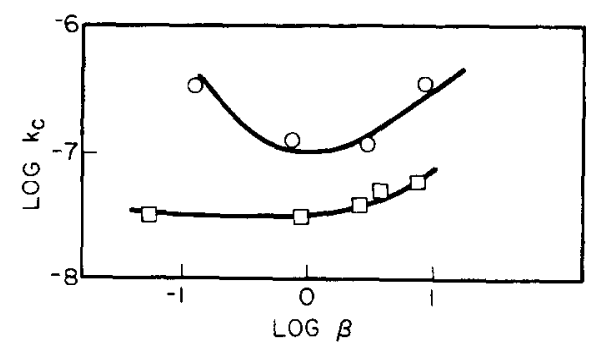

FIG. 9. $k_{c}$ versus $p_{\mathrm{X}} / p_{\mathrm{TO}}=\beta$ for a mixed feed of $o$-XE $(\square)$; and $p$-XE (O); in reaction (1), catalyzed by $\mathrm{Pt}-\mathrm{Al}_{2} \mathrm{O}_{3}, 390^{\circ} \mathrm{C}$.

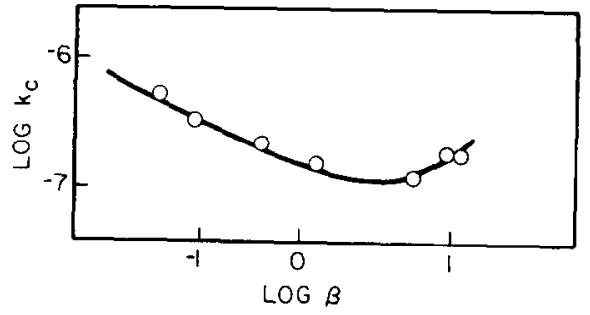

FIG. $10 . k_{c}$ versus $p_{\mathrm{EBE}} / p_{\text {TO }}=\beta$ for reaction (1) catalyzed by $\mathrm{Pt}-\mathrm{Al}_{2} \mathrm{O}_{3}, 390^{\circ} \mathrm{C}$.

1. The rate of the isotopic redistribution of carbon between the hydrocarbon mixtures, BE-TO, BE-EBE, TO-EBE, TO$\mathrm{XE}, \mathrm{CHA}-\mathrm{MCH} \Lambda$, was readily catalyzed

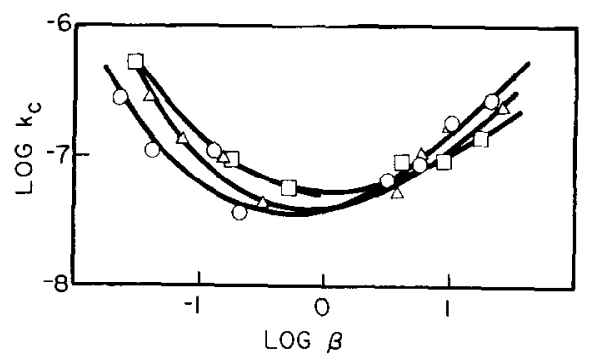

Fig. 11. $k_{c}$ versus $p_{\mathrm{MCHA}} / p_{\mathrm{CHA}}=\beta$ for reaction (1) catalyzed by $\mathrm{Pt}-\mathrm{Al}_{2} \mathrm{O}_{3}:(\triangle) 287^{\circ} \mathrm{C}$; $\left.\square\right) 335^{\circ} \mathrm{C}$; (॰) $376^{\circ} \mathrm{C}$.

by supported noble metals in the temperature range 187 to $390^{\circ} \mathrm{C}$.

2. With hydrocarbon ratios 0.01 to 30 , the rate of redistribution was dependent upon the gas phase composition: in the mixture BE-TO it increased or decreased on all catalysts studied. A similar effect was

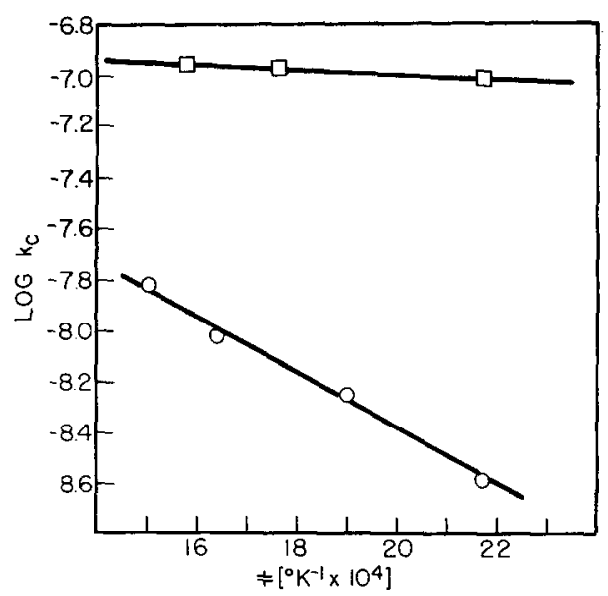

Fig. 12. Arrhenius plot for reaction (1) between $\mathrm{BE}$ and $\mathrm{TO}$ on Pt-fluorided $\mathrm{Al}_{2} \mathrm{O}_{3}(\odot)$; and between TO and $p$-XE on $\mathrm{Pt}-\mathrm{Al}_{2} \mathrm{O}_{3}$ (). 
noted for the mixture BE-EBE. At the higher values of $\beta$ there was a tendency for the relation between $k_{c}$ and $\beta$ obtained over $\mathrm{Pt}-\mathrm{Al}_{2} \mathrm{O}_{3}$ fluorided to change sign. In the redistribution reaction between $\mathrm{TO}$ and $\mathrm{XE}, \mathrm{TO}$ and EBE, CHA and MCHA, the rate decreased and subsequently increased as the ratios $p_{\mathrm{XE}} / p_{\mathrm{TO}}, p_{\mathrm{ERE}} / p_{\mathrm{TO}}, p_{\mathrm{MCHN}} /$ $p_{\text {CIS }}$, respectively, increased.

3 . The analytical dependence of the reaction rate upon the hydrocarbon ratio was also a function of other factors, namely, chemical nature of the metal present in the supported catalysts, type of $\mathrm{XE}$ isomer in the mixture TO-XE, method of catalyst preparation for supported $\mathrm{Au}$ and, finally, temperature. Essentially the reported rate experiments are concerned with the reactive adsorption isotherms of two hydrocarbons pre ent simultaneously at the same surface; and the effects noted are an indication of a basic characteristic of the adsorption of gas mixtures:adsorbate displacement by gas phase addition of a second component.

Let us consider a system containing a gaseous mixture of $\mathrm{A}$ and $\mathrm{AR}$ species equilibrated in the presence of a reactive surface according to reaction step (1a). The equilibrium condition is: $[\mathrm{R}(\mathrm{s})]=K\left(p_{\mathrm{AR}} / p_{\Lambda}\right)$ $\propto p_{\mathrm{R}}$ where $K$ is the equilibrium constant of reaction (1a) and $p_{\mathrm{R}}$ the equilibrium partial pressure of species $R$ in the gas phase. Two viewpoints may be followed in discussing the nature of the adsorbate $\mathrm{R}(\mathrm{s})$. For localized adsorption, $R(s)$ may be characterized by the number of surface attachments (sites) per each adsorbate species (single or polysite adkorption). Alternatively, for nonlocalized adsorption, R(s) may be distinguished by the extent of surface area occupied by each adsorbate molecule. The former is mostly a consequence of the relative orientations of the adsorbate and the surface. In both instances, however, the presence of adsorbate species differing in their adsorption mode induces variations in the adsorption strength and in the fraction of surface covered by each type of adsorbate. Let us consider for clarity the situation of two types of $R(s), R^{\prime}$ and $R^{\prime \prime}$, such that $\left[R^{\prime}\right] \ll$ $\left[R^{\prime \prime}\right]$ and $\left[R^{\prime \prime}\right] \cong\left[R^{\prime \prime}\right]_{\text {max }}$. These condi- tions mean that $\mathrm{R}^{\prime \prime}$ is strongly and $\mathrm{R}^{\prime}$ weakly adsorbed. Assuming nonlocalized adsorption the correct analytical relationship has been derived recently (6) and it is given by:

$$
\left[R^{\prime}\right]=C p_{\mathrm{R}}^{1-\left(\omega^{\prime} / \omega^{\prime \prime}\right)}=C^{\prime}\left(\frac{p_{\mathrm{AR}}}{p_{\mathrm{A}}}\right)^{1-\left(\omega^{\prime} / \omega^{\prime \prime}\right)}
$$

where ${ }^{\prime}$ and ( $"$ " are constants and $\omega$ represents the area of the surface occupied by each $R^{\prime}$ and $R^{\prime \prime}$ species, respectively. An essentially similar conclusion lexcept for the numerical values of the exponent in $\mathrm{Eq}$. (4) ] is obtained assuming a model of localized adsorption. Equation (4) shows that for $\omega^{\prime}>\omega^{\prime \prime} \mathrm{R}^{\prime}$ varies inversely with $p_{\mathrm{R}}$ (or the ratio $p_{\mathrm{AR}} / p_{\mathrm{A}}$ ), while the converse is valid for $\omega^{\prime}<\omega^{\prime \prime}$. Whenever $\omega^{\prime} \cong \omega^{\prime \prime}, \mathrm{R}^{\prime}$ becomes independent of $p_{R}$ (and of the ratio $p_{\mathrm{AR}} / p_{\mathrm{A}}$ ). This conclusion is important for the interpretation of the kinetics of isotopic exchange reactions of the type of reaction (1).

Ict us assume that the configuration $\mathrm{R}^{\prime}$ of $R(s)$ is the kinetically significant one for the exchange reaction (1). Then, in Eq. (2) the rate coefficient will be a function of $\mathrm{R}^{\prime}$. This may be expressed as

$$
k_{c}=k^{\prime \prime}\left[R^{\prime}\right]=k^{\prime} p_{\mathrm{R}}^{ \pm m}=k\left(\frac{p_{\mathrm{AR}}}{p_{\mathrm{A}}}\right)^{ \pm m},
$$

where $k$ is the rate constant of reaction (1). Comparison of Eqs. (4) and (5) gives $m=1-\left(\omega^{\prime} / \omega^{\prime \prime}\right)$. In the present case it is not certain whether the model of localized adsorption is valid in contrast to that of nonlocalized adsorption. Therefore in the following discussion of the experimental results, only the presence or absence of broad differences between adsorption modes of $\mathrm{R}$ will be emphasized. The question of the exact nature of these differences must be left open. High values of $m(\approx \pm 1)$ will be taken as an indication of relatively large differences. Conversely for $m \cong 0$. A change in the sign of $m$ is difficult to interpret unambiguously. It is an indication of a basic shift in the relative values of $\omega^{\prime}$ and $\omega^{\prime \prime}$.

In reaction step (1a) taking place between the following couples of hydrocarbons: BE-TO, TO-XE, CHA-MCHA, $\mathrm{R}(\mathrm{s})$ is formally a $\mathrm{CH}_{2}$ group, and a $\mathrm{Cl}_{2} \mathrm{H}_{4}$ 
molecule for the couple BE-EBE. However, it is doubtful whether independent adsorbed $\mathrm{CH}_{2}$ (or $\mathrm{C}_{2} \mathrm{H}_{4}$ ) groups are required to carry out reaction (1). One might conceive surface $\mathrm{CH}_{2}$ groups originating from, but still attached to, adsorbed alkylbenzene, viz, for the case of BE-TO: isotopic reaction. From Table 2 we conclude that by increasing the temperature, differences between adsorption types tend to disappear. Intuitively, this is the correct direction. Considering the results from Tables 1 and 2 at $390^{\circ} \mathrm{C}$, differences in adsorption decreased in the following sequence

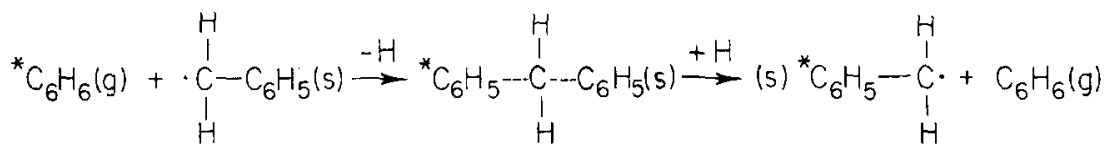

According to this picture, the surface intermediate (I) is similar to an arylmethane (or cyclohexylmethane for CHA-MCHA). Support for this model comes mainly from studies on the catalytic disproportionation of $\mathrm{TO}$ and isomerization of $\mathrm{XE}$. In these investigations, the presence of arylmethane intermediates have been firmly established $(\boldsymbol{\gamma})$. It should also be recalled that diphenylcarbonium ions (benzhydryl cations) have been observed in acid solutions (8), and that recent studies on the reactions of arylmethanes catalyzed by $\mathrm{SiO}_{2}-\mathrm{Al}_{2} \mathrm{O}_{3}$ showed that in the case of diphenylmethane the primary reaction involved alkylation (9). It is also possible to surmise that $\mathrm{R}(\mathrm{s})$ corresponds to an alkyl group whose transfer between $A R$ and $A$ is accompanied by hydrogen transfer in the opposite direction. Adsorption of aromatic hydrocarbons by $\pi$-bond complexing may preserve the integrity of the alkyl group in the adsorbed state. The values of the exponent $m$ [Eq. (5) ] were calculated from the experimental results. In a few instances the plot of $\log k_{e}$ vs $\beta$ was curvilinear. The linear parts of these plots were used in the computation of the value of $m$. They are reported in Tables 1 to 4 .

The low values of $m$ reported in Table 1 for $\mathrm{Ru}, \mathrm{Ir}$, and $\mathrm{Au}$ indicate that there was a relatively small difference in the adsorption characteristics of the reaction intermediate. Addition of $\mathrm{NaOH}$ did not modify this condition, while the method of preparation of Au (but not the support) introduced drastic modifications in the adsorption step controlling the rate of the of supported metals: $\mathrm{Ru}>\mathrm{Pt}>\mathrm{Ir}, \mathrm{Au}>$ $\mathrm{Pt}$ acidic. Noteworthy in this sequence are the following: the position of $\mathrm{Ru}$, the effect of catalyst acidity, the apparent lack

TABLE 1

Avtikage Valuks of the Ratio $\partial \ln k_{c} / \partial \ln \beta=m$ and of the Irate Constant $k$ for Reaction

(1) CAtalyzed $\mathrm{BY} \mathrm{Al}_{2} \mathrm{O}_{3}$ Supponted Metals, $390^{\circ} \mathrm{C}$, BE-To Mixture

\begin{tabular}{ccc}
\hline Catalyst. & $m$ & $\begin{array}{c}k \times 10^{7} \\
\mid \mathrm{mole} / \mathrm{g} \text { (cat) see atm] }\end{array}$ \\
\hline $\mathrm{Ru}$ & $\sim 0$ & 0.02 \\
$\mathrm{Ir}$ & 0.21 & 0.19 \\
$\mathrm{Ir}$ & 0.21 & 0.13 \\
$\mathrm{Au}$ & 0.20 & 0.14 \\
$\mathrm{Au}$ & -0.10 & 0.58 \\
$\mathrm{Au}^{b}$ & -0.10 & 0.35 \\
\hline
\end{tabular}

a Containing $\mathrm{NaOH}$.

${ }^{b}$ Prepared by reduction.

c Prepared by reduction on $\mathrm{MgO}$ support.

TABLE 2

AVERAGE ViLUES of $\partial \ln k_{c} / \partial \ln \beta=m$ AND THE Rate Constant $k$ for Reaction (1) With BE-TO Mixtures Over Pt- $\mathrm{Al}_{2} \mathrm{O}_{3}$ FLUORIDED

\begin{tabular}{ccc}
\hline $\begin{array}{c}\text { Temp } \\
\left({ }^{\circ} \mathrm{C}\right)\end{array}$ & $m$ & $\begin{array}{c}k \times 10^{7} \\
{[\mathrm{~mole} / \mathrm{g}(\mathrm{cat}) \mathrm{sec} \mathrm{atm}]}\end{array}$ \\
\hline 185 & 0.02 & 0.03 \\
255 & 0.06 & 0.05 \\
338 & 0.22 & 0.09 \\
390 & 0.27 & 0.19 \\
$390^{a}$ & 0.14 & 0.20 \\
$390^{b}$ & 0.40 & 0.06 \\
\hline
\end{tabular}

a Nonacid P.

b BF-FBF, mixtures. 
TABLE 3

Average Values of the Ratio $\partial \ln k_{c} / \partial \ln \beta=m$ and Rate Constant $k$ for Reaction (1) Over $\mathrm{Pt}-\mathrm{Al}_{2} \mathrm{O}_{3}$

\begin{tabular}{lccc}
\hline $\begin{array}{c}\text { Hydro- } \\
\text { carbon } \\
\text { mixture }\end{array}$ & $\begin{array}{c}\text { Temp } \\
\left({ }^{\circ} \mathrm{C}\right)\end{array}$ & $m$ & $\begin{array}{c}k \times 10^{7} \\
{[\mathrm{~mole} / \mathrm{g}(\mathrm{cat})} \\
\text { sec atm] }\end{array}$ \\
\hline TO-o-XE & 400 & $-0.92,0.44$ & 0.63 \\
TO- $m$-XE & 400 & $-0.90,0.44$ & 1.05 \\
TO- $p$-XE & 210 & $-0.93,0.50$ & 1.00 \\
TO-o-XE & 327 & $-0.92,0.50$ & 1.15 \\
TO- $p$-XE & 400 & $-0.90,0.50$ & 1.15 \\
TO-EBE & 400 & $-0.40,0.60$ & 1.42 \\
CHA-MCHA & 287 & $-0.63,0.70$ & 0.40 \\
CHA-MCHA & 335 & $-0.60,0.70$ & 0.60 \\
CHA-MCHA & 376 & $-0.60,0.70$ & 0.40 \\
\hline
\end{tabular}

of correlation with chemical or electronic properties of the metals. It is also interesting to note the large effect obtained on $\mathrm{Pt}$ catalysts at $390^{\circ} \mathrm{C}$ when $\mathrm{TO}$ is substituted with EBE. The value of $m$ changed from 0.27 to 0.40 , showing that the nature of the adsorption was affected by the molecular weight of the group transferred.

Table 3 shows that the values of $m$ for the mixture of TO and the three XE isomers, taken individually, are similar, indicating that the nature of the $\mathrm{XE}$ isomer did not influence the adsorption characteristics. However, in binary isomeric mixtures (Table 4), the inverse relation between $k_{c}$ and $\beta$, present at low $\beta$, was modified. Thus, the adsorption at low $\beta$ is affected by the nature of the XE isomer.

Tables 1 to 4 contain in the last column the values of the reaction rate constant $k$ [Eq. (5)]. In mixtures with TO the order of

\section{TABLE 4}

Average Valuks of the Ratio $\partial \ln k_{c} / \partial \ln \beta=m$ and Rate Constant $k$ for Reaction (1)

Between TO and a Mixture of XF Isomers Over $\mathrm{Pt}-\mathrm{Al}_{2} \mathrm{O}_{3}, 400^{\circ} \mathrm{C}$

\begin{tabular}{ccrc}
\hline $\begin{array}{c}\text { Hydrocarbon } \\
\text { mixture }\end{array}$ & $\begin{array}{c}\text { Hydro- } \\
\text { carbon }\end{array}$ & $m$ & $\begin{array}{c}k \times 10^{7} \\
\text { [mole/ } \\
\text { g(cat) } \\
\text { sec atm] }\end{array}$ \\
\hline TO-o-XE-p-XE & $o-\mathrm{XE}$ & $\sim 0,0.41$ & 0.33 \\
& $p$-XE & $-0.45,0.50$ & 2.10 \\
TO-o-XE-m-XE & $o-\mathrm{XE}$ & $-0.40,0.40$ & 0.25 \\
& $m-\mathrm{XE}$ & $-0.43,0.40$ & 0.80 \\
\hline
\end{tabular}

increasing reactivity at $400^{\circ} \mathrm{C}$ is (Table 1 ) $\mathrm{EBE}>p$-XE $>0$-XE. The result parallels the known ease of catalytic hydrogenation (10). In addition, the higher rate of $\mathrm{EBE}$ ( $>2$ times that of $o-\mathrm{XE})$ is in accord with the observation that the rate of alkylation increases with the molecular weight of the alkyl group. This is in line with carbonium ion theory, which predicts a relatively easier formation of ethyl than methyl carbonium ion (11). The higher reactivity of $\mathrm{TO}$ and $\mathrm{EBE}$ in relation to $\mathrm{BE}$ may be related to the presence of weak benzylic hydrogens in the former compounds. To test this interpretation it would be interesting to use $t$-butylbenzene. With no bezylic $\mathrm{C}-\mathrm{H}$ bonds the reactivity in this latter case should be lower than that of TO and EBE. In the case of the CHA-MCHA mixture, alkyl transfer took place at a lower rate than in the case of $\mathrm{XE}$ and was practically independent of the temperature. The experiments involving the simultaneous presence of two XE isomers showed that the transfer rate for the o-isomer was halved by the presence of the $p$ or $m$ isomer. For the $m$ isomer the rate decreased by $\sim 20 \%$ by the addition of the $o$-isomer, while for the $p$-isomer it increased by a factor of two with the addition of the $o$-isomer. Highly acidified catalyst support did not influence the kinetic aspect of the reactivity of $\mathrm{Pt}$ (Table 3). This is consistent with an increasing body of evidence showing that reactions of ring opening and alkyl transfer catalyzed by solid surfaces may take place in the absence of added acidity (12). In previous studies on the hydrodealkylation of methylaromatics over $\mathrm{Cr}_{2} \mathrm{O}_{3}-\mathrm{Al}_{2} \mathrm{O}_{3}$ catalysts (1), the activity of the catalyst was found independent of the acidity of the support $\mathrm{Al}_{2} \mathrm{O}_{3}$. In fact, it was observed that changes in the acidity of the $\mathrm{Al}_{2} \mathrm{O}_{3}$ which would have caused a $100: 1$ ratio of activities for acid catalyzed reactions did not affect the activity of the $\mathrm{Cr}_{2} \mathrm{O}_{3}-\mathrm{Al}_{2} \mathrm{O}_{3}$ catalyst for TO dehydrodealkylation. From Table 4, the sequence of rate constants at $390^{\circ} \mathrm{C}$ for the $\mathrm{BE}-\mathrm{TO}$ transfer is $\mathrm{Pt}>$ $\mathrm{Ir}>\mathrm{Au}>\mathrm{Ru}$. There was a small $(\sim 20 \%)$ decrease in the rate constant when $\mathrm{Na}$ was present at the $\mathrm{Ir}$ surface, but a large increase ( $>4$ times) in the rate constant in 
Au by preparing it by reduction. Recently the dealkylation of $\mathrm{TO}$ was studied over siupported piatinum metals at 300 to $500^{\circ} \mathrm{C}$ in the absence of added $\mathrm{H}_{2}$ or steam (13). The observed activity sequence was $\mathrm{Rh}>$ $\mathrm{Pt}>\mathrm{Pd}>\mathrm{Ir} \simeq \mathrm{Ru} \approx \mathrm{Os}$. This is remarkably similar to that observed in this work, indicating that reaction (1) reflects in important kinetic aspects the characteristics of net alkylations. It is interesting also to note that, in the presence of hydrogen, the hydrodealkylation activity sequence was different from that obtained in its absence and more closely related to that obtained in the hydrogenenoiysis of ethane (14).

\section{Conclusion}

This study has demonstrated that reaction (1) may be readily followed under mild catalytic conditions; and its rate measured quantitatively without spurious interference from side reactions. The kinetic effects noted are the result of the competitive reactive adsorption of the corresponding hydrocarbon mixtures. The former are influenced by the nature of the hydrocarbons, type of isomer, surface, catalyst support and temperature. The method employed permits the characterization of the kinetics of individual alkyl transfer steps, whose systematic investigation should produce broad correlations for the prediction of the behavior of net alkylation reactions.

\section{ACKNOWLEDGMENTS}

We express our thanks to Drs. V. Haensel and H. S. Bloch of the Universal Oil Products Company for their encouragement, stimulating disrussions and for the supply of the $\mathrm{Pt}$ catalysts mployed in this work. This research was supported by grants from the Petroleum Research
Fund, administered by the American Chemical Society, the H, H. Rackham School of Graduate Studies of The University of Michigan, and the National Science Foundation. This support is gratefully acknowledged.

\section{REFERENCES}

1. Notari, B., Durantit Valentini, P., and De Maldé, M., Proc. Int. Congr. Catal., Brd, 1964, 1034 (1965).

2. Parravano, G., J. Catal. 16, 1 (1970).

8. Cha, D. Y., and Parravano, G., J. Catal. 18, $200(1970)$.

4. Ipatielf, V. N. Komarewski, V. N., and Grosse, V. I., J. Amer. Chem. Soc. 57, 1722 (1935) ; Rudenko, A. P., Budrina, D. E., and Baldandin, A. A., Dokl. Akad. Nauk SSSR 165, 874 (1965); Minachev, Kh. M., and Isakov, Ya. I., Dokl. Akad. Nauk SSSR 170, 99, 831 (1966); Panchenkov, G. M., Kolesnikov, I. M., and Morozov, E. A., Zh. Fiz. Khim. 40, 526 (1966); Venuto, P. B., Ind. Eng. Chem., Prod. Res. Develop. 6, 190 (1967).

5. SнUікім, D. A., Zh. Obshch. Khim. 33, 3871 (1963).

6. Wariner, C. Ber. Bunsenges. Phys. Chem. 74, $398(1970)$.

7. Ianawala, M. A., and Bolton, A. P., presented N. Amer. Meet., Catal Soc,, 1st, Atlantic City, Feb., 1969.

8. Olah, G. A., J. Amer. Chem. Soc. 86, 934 (1964).

9. Wu., C.-Y., Porter, R. P., and Hall, W. K., J. Calal. 19, $277(1970)$.

10. Wanquier, J. P., and Jungeis, J.C., C. Acad. Sci. 243, 1766 (1956).

11. Streitwieser, A., Chem. Rev. 56, 614 (1956).

12. Lester, G. R., J. Catal. 13, 187 (1969).

19. Dydykina, G. V., Rabinovich, G. I., Maslyanski, G. N., and Dement'eva, M. I., Kinet. Catal. (USSR) 10, 497 (1969).

14. Sinfelt, J. H., ANd Yates, D. Y, J. Catal. 8, 82,348 (1967). 